\title{
Urdimento
}

Revista de Estudos em Artes Cênicas

E-ISSN: 2358.6958

\section{La calle como espacio escénico y como vocación: algunas reflexiones sobre el teatro callejero en Buenos Aires}

Francesca Rindone

\section{Para citar este artigo:}

RINDONE, Francesca. La calle como espacio escénico y como vocación: algunas reflexiones sobre el teatro callejero en Buenos Aires. Urdimento, Florianópolis, v. 2 , n. 38, ago./set. 2020.

DOI: http:/dx.doi.org/10.5965/14145731023820200011

Este artigo passou pelo Plagiarism Detection Software | iThenticate 
La calle como espacio escénico y como vocación: algunas reflexiones sobre el teatro callejero en Buenos Aires

Francesca Rindone ${ }^{1}$

\begin{abstract}
Resumen
En este artículo queremos presentar algunas reflexiones acerca del teatro callejero de grupos en la ciudad de Buenos Aires en la actualidad. Se trazarán algunas líneas teórico-metodológicas para abordar la noción de popular en el ámbito teatral, atingiendo a la fuente de los estudios culturales, teatrales y antropológicos, para poder analizar en un segundo momento algunas narrativas de los protagonistas de este lenguaje teatral. Asimismo, se presentará brevemente la historia de un grupo en particular, elegido como referente en la ciudad de Buenos Aires: el grupo La Runfla, activo desde el año 1991, cuyas actividades artísticas se concentran en el Parque Avellaneda y contribuyeron a la recuperación de este espacio público.
\end{abstract}

Palabras-clave: Teatro callejero. Espacio público. Popular.

The street as a performing stage and as a vocation: some reflections on street theatre in Buenos Aires

\begin{abstract}
In this article we want to introduce some reflection on colective street theatre in the city of Buenos Aires in the last years. We will draw some theorical and methodological lines to approach the concept of popular in the theatrical area, attending to cultural studies, theatrical theories and anthropology, and analyze in a second step some experiences narrated by actors of street theatre. We will also introduce briefly the story of a group which is recognized as a reference of street theatre in Buenos Aires: La Runfla, founded in 1991, who's political and artistical activities take place in Parque Avellaneda and contributed to the revaluation of this public space.
\end{abstract}

Keywords: Street theatre. Public space. Popular.

${ }^{1}$ Licenciada en Comunicación Intercultural por la Universidad de Torino (Italia) y Magister en Antropología Cultural y Etnología por la Universidad de Torino (Italia) Doctoranda en Antropología por la Universidad de Buenos Aires. Instituto de Ciencias Antropológicas de la Facultad de Filosofía y Letras de la Universidad de Buenos Aires. francesca.rindone@gmail.com 
El teatro callejero es un lenguaje artístico que presenta múltiples complejidades, posibles de abordar desde diferentes tipos de estudio: en el trabajo que aquí presentamos la mirada antropológica se complementa con importantes aportes de los estudios culturales y teatrales.

Delimitar el concepto de teatro callejero parece una tarea simple, ya que este lenguaje teatral se define a partir de su espacio escénico, pero en la práctica no es tan sencillo. Si tomáramos en consideración solamente el espacio físico, geográfico, como criterio para delimitar el concepto, encontraríamos allí una infinidad de performances artísticas que toman lugar en el espacio público, pero no necesariamente confluirían en lo que aquí analizamos como teatro callejero.

Aquí deseamos destacar el trabajo de los artistas que se dedican al teatro en grupo produciendo obras teatrales adaptándolas - o directamente pensándolas para un espacio abierto y/o no convencional. El caso específico que condensa este tipo de experiencias hoy en día en Buenos Aires es el del Grupo La Runfla, fundado en 1991 a partir de la fusión de dos grupos preexistentes (La Obra y El Encuentro), y dirigido por Héctor Alvarellos, ya ligado al teatro callejero por haber integrado el Teatro de la Libertad en los años 1980.

Desde la mitad de los años 1990 La Runfla concentra sus actividades artísticas en el Parque Avellaneda: uno de los pocos parques públicos de la ciudad, situado en un barrio de clase media-baja alejado del centro de la ciudad (comuna 9 de la Ciudad Autónoma de Buenos Aires).

El grupo, como veremos, contribuyó a la recuperación de este parque público a lo largo de la década del 90 junto a otras asociaciones vecinales, llegando a obtener la gestión asociada del espacio a través de una Mesa de Trabajo y Consenso, y en el 2004 incluso instaló allí una escuela de teatro callejero, el Curso de Formación del Actor-Actriz para la Actuación en Espacios Abiertos, que se encuentra entre las ofertas formativas de la Escuela Metropolitana de Arte Dramático (EMAD) ${ }^{2}$.

2 En otros trabajos (Rindone, 2019) hemos analizado el recorrido que llevó a la inclusión del Curso de Formación del Actor-Actriz para la Actuación en Espacios Abiertos entre las ofertas formativas de la Escuela Metropolitana de Arte Dramático (EMAD). El curso tiene una duración de dos años, de lunes a viernes de 
Los artistas y grupos teatrales callejeros que gravitan alrededor de este territorio eligen hacer teatro en la calle, de acuerdo con determinados valores y con precisas narrativas acerca del espacio público, quiénes lo habitan y quienes lo gobiernan. La premisa que guía este trabajo es, de acuerdo con estas narrativas, que la calle como espacio escénico no es una opción residual, sino una precisa elección poética, estética y política. El objetivo de este trabajo es compartir algunas reflexiones acerca de las experiencias de estos actores y actrices, de acuerdo con las líneas de investigación anteriormente mencionadas y dando cuenta del recorrido histórico de este lenguaje artístico en la ciudad.

\section{Líneas teóricas: analizar lo popular}

Según el Diccionario de Teatro del francés Patrice Pavis, la decisión de hacer teatro afuera del edificio teatral responde al deseo de llevar el teatro a un público que normalmente no tiene acceso a este tipo de espectáculos, produciendo así un impacto sociopolítico directo que entrecruza la participación cultural y la manifestación social (Pavis, 1998). En este sentido, más que de una delimitación física del espacio escénico, habla de la elección de interactuar con un determinado tipo de público, a menudo identificado como popular.

En la Argentina, el teatro popular tiene una historia muy particular, presenta determinadas características de actuación, una precisa relación con el texto dramático y con el público, y una específica concepción del trabajo de actores y actrices (Pellettieri, 2001; Mauro, 2011, 2013), pero se asocia generalmente con el teatro de sala.

Por lo tanto, aquí el termino popular (si bien tiene mucho en común con lo anteriormente mencionado) es de tomar principalmente como contraposición a dominante/culto, y en relación con lo teatral es oportuno utilizar el concepto bajtiniano (Bajtín, 1994) de carnavalización, en el cual se identifica al carnaval como 
hecho social privilegiado donde la cultura popular se propone como parodia de la dominante.

No es intención tratar lo popular de una forma puramente descriptiva: sería imposible, ya que no se puede pensar esta categoría por fuera de la dialéctica; en efecto, las bases de lo popular son justamente "las tensiones y las oposiciones entre lo que pertenece al dominio central de la cultura de élite o dominante y la cultura de la 'periferia'." (Hall, 1984, p. 6).

Esta dialéctica central/periférico es particularmente útil a los fines de nuestro estudio, ya que como mencionado anteriormente estamos tomando a ejemplo grupos de teatro callejero que actúan en un espacio periférico de la ciudad metropolitana de Buenos Aires: una vez más, esta oposición se extiende desde el ámbito de lo puramente geográfico al de la clasificación de los lenguajes artísticos. De hecho, el teatro callejero como lenguaje artístico popular busca continuamente disputar su espacio legítimo dentro del campo teatral, entendido como espacio social de acción y de influencia en el que confluyen relaciones sociales determinadas. (Bourdieu, 1990).

Delimitar la noción de popular ha sido y sigue siendo, también una inquietud de la antropología, que a menudo lo ha hecho sirviéndose de metáforas teatrales.

Tomemos como ejemplo estas palabras de Néstor García Canclini: “Lo popular, conglomerado heterogéneo de grupos sociales, no tiene el sentido unívoco de un concepto científico, sino el valor ambiguo de una noción teatral: lo popular designa una posición de ciertos actores, la que los opone a los hegemónicos." (García Canclini, 1987, p. 19).

Una vez más, la dimensión dialéctica se vuelve clave para definir lo popular, aquí contrapuesto con lo hegemónico: este término introducido por Antonio Gramsci (2019) desató una serie de perspectivas que, desde el marxismo, buscaron pensar las prácticas culturales y los sistemas simbólicos en términos de disputas por el poder en una sociedad, teniendo en cuenta de las desigualdades y las relaciones de fuerza. Podemos además entender la inquietud de llevar el teatro a la calle como una forma de democratización cultural (García Canclini, 1987) en 
cuanto estas teatralidades buscan ampliar el acceso a los bienes culturales a favor de los sectores populares. Insistir sobre la elección del espacio público como espacio escénico implica remarcar que el arte es un derecho cultural, si bien existan amplios márgenes de ambigüedad alrededor de esta categoría ya que en muchos aspectos aún siguen siendo derechos "de segunda." (Achugar, 2003; Raggio, 2013).

Algunos protagonistas de la historia del teatro callejero también produjeron teorías e interpretaciones sobre sus experiencias: Enrique Dacal, director del Teatro de la Libertad, en el homónimo libro define el teatro de calle como una "verdadera tradición de teatro popular" (cursiva de la autora) que "nunca ha tenido buena relación con las clases dirigentes y que ha sufrido desprecio por gran parte del establishment cultural” (cursiva original, Dacal, 2006, p. 13). Nuevamente llama la atención la ductilidad de la categoría popular aún más cuando está asociada a la de tradición que lejos de ser el mero mantenimiento de formas antiguas "tiene mucho más que ver con la forma en que se han vinculado o articulado los elementos unos con otros" (Hall, 1984, p. 8). Estamos hablando pues de tradiciones selectivas: es decir, de precisas selecciones de elementos del pasado en una perspectiva de configuración del presente. (Williams, 2009).

\section{El teatro callejero de grupos en Buenos Aires}

El teatro callejero de grupos en la ciudad de Buenos Aires tiene la particularidad de ahondar sus raíces en la experiencia de los grupos de teatro militante en los años anteriores a la última dictadura cívico militar; estos colectivos cuestionaron fuertemente las significaciones legitimadas acerca del arte, con el fin de desdibujar los límites entre el teatro y la política, la vida social y el espacio público.

En esta época, aparecieron narrativas que vinculaban el actuar en la calle con la vocación de "acercar el teatro al pueblo" y la inquietud de re-definir el arte en términos populares, no elitistas y políticamente comprometidos (Verzero, 2013). Según García Canclini, la comunidad de artistas de esta época buscaban enlazar 
la crítica a las instituciones de élite y a la sociedad opresora con modelos utópicos de vida social (García Canclini, 2010). Podemos identificar esta idea como una matriz desde la cual se desprendieron múltiples formas del quehacer teatral, numerosos abordajes a la dramaturgia y a la puesta en escena, así como diferentes ideologías políticas que se reflejaban en distintas maneras de articular la práctica teatral con la militancia.

Verzero señala como las experiencias de teatro militante de los años 70 buscaron una ruptura con los espacios artísticos convencionales, resignificando espacios no pensados para el teatro, penetrando en territorios donde nunca había llegado: en otras palabras, buscaban reinventar la relación del teatro con su espacio escénico. A los fines de clarificar nuestro recorrido histórico hacia el estudio del teatro callejero en la actualidad, compartimos aquí su distinción entre lugar, espacio y territorio.

Según Michel de Certeau (2007), el lugar es el ordenamiento a partir del cual los elementos que lo ocupan entablan relaciones de coexistencia: "Un lugar es pues una configuración instantánea de posiciones” (Certeau, 2007, p. 129). Al contrario, el espacio conlleva la idea de desplazamiento: "es un entrecruzamiento de movilidades [...] Espacio es el efecto producido por las operaciones que lo orientan, lo circunstancian, lo temporalizan y lo llevan a funcionar como una unidad polivalente de programas conflictuales o de proximidades contractuales" (Certeau, 2007, p. 129). La autora entrecruza los dos conceptos afirmando que:

El espacio se construye a partir de un sistema semiótico que otorga significación a un lugar. La interpretación de dicho sistema de signos posibilita el acceso a la significación del espacio. De esta manera, por ejemplo, la calle, que es a priori un lugar, se transforma en espacio al ser intervenida y se carga de valor simbólico al ser interpretada. (Verzero, 2013, p. 267).

Finalmente el territorio, cuya etimología remite a una extensión de tierra habitada por una comunidad, tiene la peculiaridad de poderse delimitar y representar cartográficamente, además de definirse partir de valoraciones sociales. Siempre en palabras de la autora "un suelo habitado por una comunidad 
está cargado de significaciones sociales, que surgen de las interacciones al interior de esa comunidad y de las relaciones que ese grupo social entabla con otros" (Verzero, 2013, p. 267). Llevando su teatro a los barrios, los grupos de teatro militante buscaban disolver las distinciones sociales entre los artistas y los sectores populares, pero terminaban reforzando-las y exponiéndolas por el hecho mismo de trasladar las experiencias artísticas. Uno de los objetivos principales de las experiencias culturales militantes ha sido abandonar la institución arte y llevar las producciones artísticas a los espacios habitados por los sectores populares.

Anticipamos aquí que, en el teatro callejero contemporáneo, la inquietud de "Llevar el teatro al pueblo" se configura no tanto en la intervención artística en espacios donde "no llega el teatro" - si bien esto forma parte de su discurso - sino más bien en la construcción de un territorio - el Parque Avellaneda - recuperado y habitado a través del teatro.

Como sabemos, durante la última dictadura cívico-militar argentina (19761983) numerosos protagonistas de las experiencias de teatro militante fueron secuestrados y detenidos en los Centros de Detención, Tortura y Exterminio, u obligados a exiliarse y abandonar la actividad teatral, ya que tras el golpe de estado del 24 de marzo 1976 los organismos municipales, controlados por los militares, consideraban el hecho teatral callejero como subversión. No es difícil imaginar que los años del terrorismo de Estado, en los cuales se produjo no solo la censura y prohibición de diferentes lenguajes artísticos populares, si no también una extrema reducción y represión del uso del espacio público (además de la persecución y desaparición de personas) produjo en los artistas que lo vivieron un trauma que fue necesario sanar con todos los medios posibles.

Con la vuelta de la democracia, además del re-establecimiento de los aparatos estatales constitucionales, volvió la posibilidad de manifestarse abierta y artísticamente desde lo colectivo: en este clima de entusiasmo y efervescencia cultural, se desarrollaron nuevas posibilidades de expresión que "signaron aquella conquista social y política, generando alegría en la ciudadanía y un clima de fiesta que floreció durante los primeros años de la transición.” (González, 2018, p. 69). 
A partir de 1983 se produjo pues el resurgimiento de prácticas artísticas populares prohibidas y/o censuradas durante la dictadura cívico-militar: estamos hablando, por ejemplo, del teatro callejero, el circo, la murga, el tango, entre otros (Martín, 2008; Infantino, 2014; Infantino y Morel 2015; Mercado, 2017). Según algunos estudios, los teatristas de aquella época también buscaban exorcizar los fantasmas del terror, armando un hilo conductor entre diferentes grupos a lo largo de Sudamérica que intentaban restaurar una nueva teatralidad a partir de la recuperación de la libertad después de las dictaduras (Sánchez Salinas, 2017). Esta inquietud se concretó, entre otras formas, en la organización de numerosos encuentros y festivales teatrales a lo largo de los años 80, de los cuales queremos destacar el Primer Festival Latinoamericano de Teatro en octubre 1984, en la provincia argentina de Córdoba.

En el año 1985, los grupos de teatro popular de la Argentina interesados en desarrollar una renovada estética callejera se reunieron en la Red de Teatro Popular y Animación de Base, que a su vez pasó a llamarse MOTEPO (Movimiento de Teatro Popular) en el 1987 y en el cual confluían diferentes grupos y artistas callejeros-teatristas, artistas circenses, titiriteros etc. (Dacal, 2006).

Uno de los grupos que formaron parte del MOTEPO, el Teatro de la Libertad, es considerado el punto de partida para el desarrollo del teatro callejero contemporáneo, tanto por las técnicas de entrenamiento que allí se gestaron, como por las bases ideológicas que caracterizaban el trabajo de este grupo y su elección de actuar en el espacio público. (Alvarellos, 2007).

En las décadas siguientes se produjo una desarticulación del MOTEPO, que podemos interpretar a grandes rasgos como producto de diferentes prioridades con respecto al quehacer teatral.

Una escisión notoria se produjo con el teatro comunitario, que privilegió llevar adelante el trabajo territorial construyendo comunidades en los barrios alrededor de galpones, centros culturales y demás edificios adaptados a teatros, resignando (en algunos casos) la elección de la calle como espacio artístico, mientras que el teatro callejero se aferró firmemente de esta elección, considerada como el núcleo 
central de lo popular. A pesar de tomar diferentes caminos, el teatro callejero y el comunitario mantienen hasta el día de hoy un estrecho vínculo artístico, ideológico y afectivo.

En el 1991 nace el grupo de teatro callejero La Runfla, de la unión de dos grupos preexistentes (La Obra y El Encuentro) y por iniciativa de Héctor Alvarellos, ya actor en los años anteriores a la dictadura y miembro del MOTEPO como integrante del Teatro de la Libertad, ahora en veste de director. Este grupo empezó a ensayar y realizar sus espectáculos en el Parque Rivadavia, hasta que en el 1993 Alvarellos adquirió un espacio en el barrio de Floresta, que fue transformado en el Centro Cultural La Casita de la Selva - Sala Teatral Carlos Trigo: allí se empezaron a dar unos primeros talleres de teatro.

Junto con los vecinos del barrio, se empezaron a organizar algunos festivales callejeros en el Pasaje La Selva, con actividades para los niños y números de diferentes disciplinas artísticas: se puede entonces considerar este momento como un primer brote de aquello que luego se realizará, en mayor escala y con más recursos, en el Parque Avellaneda, que en este momento se encontraba en estado de abandono. El grupo decidió, en acción conjunta con vecinos y diferentes asociaciones, emprender la recuperación del parque utilizando sus peculiares actuaciones:

La estrategia entonces fue acercar al público al corazón del Parque [...]. Con un espectáculo lúdico participativo, El Pirata Kemeim-porta, acercamos al público a la Casona, con acciones inclusivas que referían a la importancia de la participación, invitándolo a sumarse al proyecto de recuperación del Parque. (Alvarellos, 2009, p. 58).

\footnotetext{
Dicha distinción es muy sumaria, en cuanto por un lado el teatro comunitario nunca abandonó del todo la calle, ni siquiera en épocas recientes: pensemos, por ejemplo, en la obra del Circuito Cultural Barracas "Barracas al fondo" (sólo por citar una), y por otro lado el teatro callejero así como lo conocemos en el Parque Avellaneda no dejó de lado la construcción de lazos comunitarios, como veremos a continuación. Hoy en día, podemos individuar como principal diferencia entre estos dos lenguajes teatrales el nivel de profesionalismo de los actores: el teatro comunitario elige trabajar con actores-vecinos, o sea no profesionales, mientras que el teatro callejero (por lo menos el recorte que estamos analizando aquí) suele trabajar con actores de profesión. En trabajos futuros nos proponemos complejizar ulteriormente esta distinción, analizando más puntualmente y de manera crítica la categoría de lo profesional. Para profundizar en los estudios sobre teatro comunitario se recomienda la lectura de Proaño Gómez (2013), Scher (2010), Fernández (2013) y Mercado (2018).
} 
También se empezó a realizar la conmemoración del 25 de mayo de 1810 a través del espectáculo lúdico Un viaje al pasado siempre con la participación de los vecinos del barrio.

En el transcurso de la recuperación, como los edificios históricos se encontraban inhabilitados o en estado de abandono, la actividad artística del parque se desarrolló sobre todo en el espacio público, marcando una nueva impronta cultural y una apropiación de la calle por parte de las artes urbanas: así se fueron sumando, por ejemplo, el coro Vocal Cumelén, el grupo de danzas folklóricas Atipac - Ynalen, la murga Los Descarrilados de Parque Avellaneda, el grupo cultural Wayna Marka, las Danzas Circulares del Mundo, Caracú Teatro Callejero y Teatro de la Intemperie.

En el año 2000 los colectivos artísticos del parque participaron activamente en la inauguración de la Casona de los Olivera, que hasta este momento se encontraba en estado de abandono. Según el relato de los actores, más de 200 vecinos y actores, con trajes de época facilitados por el Teatro Colón, estrenaron la Casona restaurada, utilizando además "la carroza de los gobernadores comprada por el mismísimo Sarmiento y suministrada por el Museo de Luján." (Alvarellos, 2009, p. 60).

En los mismos años, La Runfla estaba trabajando al espectáculo De chacras, tambo y glorietas, que contaba la historia del Parque y que, por esta misma razón, será analizada brevemente a continuación con el fin de presentar una obra ejemplar de este grupo.

Para empezar, cabe destacar que se trata de una obra dinámica, es decir que el guion incorpora constantemente nuevas adaptaciones incluyendo en las diferentes escenas referencias a la coyuntura del momento. Este dinamismo es típico tanto en el teatro callejero como en el comunitario: de hecho, una obra en la cual se puede revisar este mismo trabajo de incorporación de elementos de la actualidad es El Fulgor Argentino del Grupo de Teatro Comunitario Catalinas Sur, en la cual se cuenta un siglo de historia argentina desde las vivencias de los asociados al club social y deportivo que da el nombre a la obra. 
En De chacras, tambo y glorietas pasa algo parecido: a través de la historia del Parque Avellaneda, se cuenta un recorte de la historia del país con referencias puntuales a la actualidad. La obra comienza en la entrada del parque, en el cruce entre la Avenida Directorio y la calle Lacarra: en este punto, aparecen los duendes del Parque Avellaneda, quienes van a buscar al público para iniciar el recorrido, con sus vestuarios llamativos de fieltro rellenos de gomaespuma y sus máscaras. Estos duendes pertenecen cada uno a una época diferente: uno viene de la época previa a la fundación de Buenos Aires, cuando el parque era territorio de las comunidades originarias Querandíes, otro es de la época colonial, etcétera. Por este motivo, en la primera escena, los duendes se pelean entre ellos, hasta que uno asume el rol de pacificador aclarando que, cómo el parque fue teatro de muchos eventos, tiene muchas - y diversas - historias para contar. Aquí el público recibe también una ficha que puede ser de color azul, verde o rosado, y servirá para saber con cual personaje continuará la segunda parte del recorrido: los espectadores que reciben la ficha azul son acompañados por el cura que trae consigo la Virgencita de los Remedios, protectora de este territorio, quienes tengan la ficha verde siguen al peón de la chacra y quienes tengan la ficha rosada siguen a la dama de caridad. Cada personaje cuenta su versión de la historia paseando por el parque con su parte de público, enriqueciendo el cuento con anécdotas aportadas por viejos vecinos y mitos populares. Los tres grupos vuelven entonces a reunirse en la entrada de la imponente Casona de los Olivera, donde se descubre que estos tres personajes son en realidad los fantasmas de las épocas pasadas, y se despiden diciendo: "Nosotros, los verdaderos fantasmas, somos los que mantenemos viva la memoria, por eso algunas personas se asustan de nosotros".

En el predio de la Casona, el público se encuentra con Domingo Olivera ${ }^{4}$ que está hablando con Nicolás Avellaneda ${ }^{5}$ y Juan Manuel de Rosas ${ }^{6}$ : los tres próceres son representados con muñecos de alrededor de 3 metros de alto, fabricados en

\footnotetext{
4 Dueño de la Casona - que lleva su nombre - hasta 1912, cuando fue vendida a la Municipalidad.

5 Presidente de la Nación Argentina (1874-1880).

6 Gobernador de Buenos Aires en dos mandatos (1829-1832 y 1835-1852).
} 
cartapesta, movidos por los actores y doblados con una voz registrada que narra los principales acontecimientos de la época.

Al terminar la escena, Olivera invita a Rosas y Avellaneda - y al público - a ingresar a la Casona para conocerla: aquí se encuentran los fantasmas de Eduardo y Carlos Olivera, sus sirvientes y una institutriz (Miss Morris). Los juegos de luces y el aspecto lúgubre de la Casona hacen todavía más sugestivo este cuento de fantasmas.

A la salida, los duendes conducen el público hasta un área del parque llamada Jardín de la Meditación, en el cual dialogan con la estatua animada de Antonio Zaccagnini, al cual se debe la ordenanza por la que se crearon las colonias de vacaciones para niños débiles en la Municipalidad de la Ciudad de Buenos Aires, que se desarrollaban en este territorio.

Desde aquí se produce otro traslado a lo que fue el primer natatorio público y mixto de la ciudad inaugurado en 1925, cuya estructura es ocupada ahora por la Escuela de Enseñanza Media n. 10 Ernesto Che Guevara: aquí, el público se encuentra con algunos bañistas que pueblan de vida este natatorio.

A la salida de esta divertida escena, aparece el toro Pancho (otro muñeco de tamaño natural construido en cartapesta) en el playón del Antiguo Natatorio, donde también se narra el proceso de deterioro del Parque Avellaneda y la posterior recuperación a partir de la iniciativa de los vecinos. La obra, estrenada en el año 2000, se mantuvo durante más de una década todos los fines de semana (salvo algunas interrupciones) en la Agenda Cultural del Parque Avellaneda, y el dinamismo que la caracteriza hizo posible que, a través de las constantes adaptaciones y referencias coyunturales, se mantuviera actualizada hasta su última función.

Reanudando el discurso previo al análisis de la obra, vemos como a partir de los años 2000 el Parque Avellaneda empezó a ser un inequívoco lugar de referencia para el teatro callejero: a raíz de este reconocimiento cada vez mayor se empezó a realizar, desde el año 2001, el Encuentro Nacional de Teatro Callejero de Grupos:

${ }^{7}$ A él es dedicada también la Escuela de Educación Primaria que se encuentra en el Parque Avellaneda. 
un evento que se repitió en forma bienal durante toda esta década, declarado de interés cultural por la Legislatura Porteña, al cual participaron numerosos colectivos de Argentina, Latinoamérica y Europa. Algunos años después, en el 2004, se creó a su vez el Curso de Formación del Actor-Actriz para la Actuación en Espacios Abiertos dependiente de la Escuela Metropolitana de Arte Dramático, destinado a formar actores especialistas en el lenguaje del teatro callejero.

La presencia del teatro callejero transformó progresivamente el Parque Avellaneda en un escenario cada vez más rico de propuestas culturales, muchas de las cuales incluidas en la Agenda Cultural de la Ciudad. Es importante destacar que la recuperación del Parque Avellaneda fue posible gracias al Plan de Manejo del año 1996: una de las estrategias que los actores culturales del Parque Avellaneda utilizaron para incidir en el campo de las políticas pública. El mismo fue ratificado en el 2003 y puesto como segunda cláusula de la Ley 1153/03, considerada por los vecinos y vecinas, actores y actrices del parque como uno de los resultados más importantes de la organización ciudadana en el territorio. Entre otras cosas, la Ley 1153/03 establece que el gobierno del Parque Avellaneda se articula en gestión asociada entre el Gobierno de la Ciudad de Buenos Aires (con un administrador y exponentes de la Secretaría de Medio Ambiente, Planeamiento Urbano y Cultura) y la Mesa de Trabajo y Consenso: una instancia de participación vecinal abierta y pública ad honorem para la planificación, gestión, monitoreo y orientación del Plan de Manejo. En reiteradas ocasiones el Gobierno de la Ciudad de Buenos Aires eludió dichos acuerdos: en estos casos, los incumplimientos fueron denunciados, además que en las sesiones de la Mesa de Trabajo y Consenso, en las mismas obras que se ponían en escena en el Parque Avellaneda, como por ejemplo la ya mencionada De chacras, tambo y glorietas, cuyo final fue muchas veces modificado para reiterar la importancia de la participación ciudadana en la gestión del parque. El teatro y los demás lenguajes culturales fueron utilizados inteligentemente en este proceso como recurso para incidir en las decisiones acerca de la gestión del espacio público. (Yudice, 2002). 


\section{¿Por qué hacer teatro en la calle? Revisión crítica de algunas categorías nativas}

Como señalamos anteriormente, el grupo que en la actualidad condensa las experiencias más notorias de actuación callejera en la ciudad de Buenos Aires es el Grupo La Runfla.

Las razones de la elección de la calle como espacio escénico están condensadas en la presentación del grupo:

En la calle están: el ciruja, la prostituta, el travesti (sic.) al que vituperan pero muchos reclaman sus servicios. En la calle están: los baches, las veredas rotas, los chorros, los drogadictos, [...]. En la calle están: la basura, la mierda de los perros [...] los escupitajos, el ruido de los escapes libres de los vehículos [...]. En síntesis; está el caos. En la calle están los barrenderos, los recolectores de residuos, el cartero, el que reparte volantes. el afilador, el que vende flores, el heladero, el pochoclero, el diariero [...]. En síntesis en la calle están todos porque la calle es de todos. En la calle está EL PUEBLO (mayúscula original) $^{8}$.

Estos actores sostienen haber elegido el espacio público porque creen encontrar ahí su principal interlocutor, que es el pueblo (con mayúscula): es una narración mítica, en la cual se condensa quizás el núcleo de la estética política de este grupo y su conceptualización de público ideal.

De estas palabras emerge además cierta cercanía/complicidad percibida con la marginalidad que habita la calle: los sectores populares constituyen un público con exigencias muy especiales. Esta consideración también es muy antigua, el mismo Antonio Gramsci observaba: "El público de los suburbios es más inteligente que el de las butacas y los escenarios. Porque no concede a la producción más que lo que merece, observa el espectáculo como observa la vida9" (Gramsci, 2012,

\footnotetext{
${ }^{8}$ Extracto de la presentación del Grupo La Runfla en su página web oficial: www/grupolarunfla.com.ar/quienes somos (consultado por última vez el 22 jun. 2020).

9 Il pubblico dei suburbi è molto più intelligente di quello chic delle poltrone e dei palchi. Perché non concede alla produzione (agli attori) più di quanto non si meritano. Osservano lo spettacolo come osservano la vita. (Traducción nuestra).
} 
p. 75). Una de las exigencias señaladas por muchos artistas callejeros (no solo los teatristas) es la de transformar los transeúntes en espectadores y mantener viva su atención a través de diferentes trucos: entrenamientos corporales y vocales, el uso del grotesco en la actuación, arreglos musicales, el uso de zancos, máscaras, muñecos y vestuarios llamativos son solamente algunos de los trucos usados en el teatro callejero.

En una de las entrevistas que forman parte del compendio Cuerpos a la Intemperie de Araceli Arreche, realizadas en ocasión del segundo Encuentro Nacional de Teatro Callejero de Grupos, una de las integrantes del grupo de teatro comunitario Alma Mate indica que una de las bases de la relación con el público es no confrontarlo. Explica la actriz:

Nosotros intentamos desde la dirección y desde la obra no invadir el espacio que no es nuestro, porque la plaza no es nuestra, es de todos [...]. Sabemos conceptualmente que la plaza tiene mil cosas más interesantes que un grupo de teatro. (Entrevista a actriz de Almamate, Arreche, 2010, p. 6).

Este es otro punto en el cual el teatro callejero (aquí teatro comunitario en su versión callejera) se diferencia de otras propuestas performáticas que toman lugar en el espacio público y que buscan provocar los transeúntes/espectadores a través de acciones escénicas chocantes ${ }^{10}$. El mensaje político, que no resulta menos incisivo, es vehiculado a través de la metáfora: de ahí la necesidad de capturar la atención del público sin invadirlo ni confrontarlo. Además, permanece en estos artistas la inquietud de mantener la atención de su público, ya que sea

10 Ejemplos de estas performances se encuentran en el trabajo de La Organización Negra en los años '80 (González, 2018), en una actitud radicalmente opuesta a la de los grupos unidos a través del MOTEPO con respecto al uso del espacio público. En la actualidad podemos mencionar las acciones de los colectivos artivistas FACC (Fuerza Artística de Choque Comunicativo), Arda y Fin de Un Mundo, que también buscan intervenir el espacio público despertando las conciencias de sus espectadores acerca de temas de actualidad (femicidios, violencia institucional, entre otros) pero que difieren ampliamente de los colectivos de teatro callejero.

No es intención de este artículo indagar profundamente en las afinidades y divergencias entre estos distintos colectivos que ocupan el espacio público ya que será material de trabajos futuros específicamente dedicados a esto: para profundizar sobre artivismo se recomienda consultar Delgado (2013) y Verzero y Manduca (2019). 
cual sea la forma en las que ha sido convocado, al no haber paredes ni butacas se puede ir en cualquier momento.

En otra entrevista de Cuerpos a la Intemperie, realizada a actores del grupo Caracú (también activo en el Parque Avellaneda), se lee:

Cuando hacemos el espectáculo de noche, si bien hay gente convocada, hay otros que pasan por el parque, ven luces y se acercan. Esa gente que está rodeada de otra gente se autoprotege sin quererlo y está en una ceremonia pública. Genera el hecho fundamental del teatro que es el encuentro. (Arreche, 2010, p. 11).

En los últimos años, gracias a las nuevas tecnologías y a las redes sociales, el horizonte de difusión de los espectáculos se ha expandido y cada vez son más las personas que se acercan a parques, plazas y otros espacios públicos para ver espectáculos de teatro callejero. Sin embargo, se mantuvo en la mayoría de las obras de teatro callejero el momento inicial de la convocatoria (generalmente musical) a través de la cual se permite al público entrar paulatinamente en la ficción teatral.

El espacio público, a menudo identificado como "peligroso" o "inseguro" se vuelve un espacio de cuidado que permite el encuentro: solo de esta manera puede acontecer el hecho teatral.

Finalmente, emerge repetidas veces desde el discurso de los actores callejeros la reafirmación de esta vocación que constituye la premisa del trabajo que estamos presentando: la decisión de hacer teatro en la calle no como una opción de descarte, sino por una precisa elección política y estética.

En una entrevista abierta en 2019 un actor de La Runfla resaltó "seguimos actuando en la calle [...] no porque no tenemos sala, sino porque es una elección estética, poética”.11

A partir de esta conceptualización, la sala teatral, que dentro de la

${ }^{11}$ Entrevista realizada el 29/09/2019 en el marco del Ciclo Memorias de la Crisis organizado por el Grupo de Estudio sobre Teatro, Política y Sociedad en América Latina. Mesa redonda con los grupos de teatro callejero La Runfla (Buenos Aires), Caracú (Buenos Aires) y La Tramoya (Santa Fe). 
clasificación de los lenguajes artísticos es percibida como la hegemonía, aparece como categoría posible: es decir, como uno de los múltiples espacios en los que podría acontecer un hecho teatral. Los actores callejeros suelen distinguir "teatro de sala" cuando normalmente esto sería llamado sencillamente "el teatro": Augusto Boal, director brasileño, resume dicha reflexión en la famosa frase "se puede hacer teatro en todas partes, inclusive en los teatros." (Boal, 2013, s/p).

\section{Conclusiones}

A través de este recorrido, quisimos trazar algunas líneas teóricas y metodológicas para el estudio del teatro callejero en Buenos Aires, cruzando los aportes provenientes de los estudios culturales y teatrales con aquellos de matriz antropológica y las elaboraciones de los datos de trabajo de campo.

Analizamos el teatro callejero como un lenguaje artístico que se define en base a su espacio escénico, ahondando en las razones de esta elección política y estética, ya que sabemos - tanto por las narrativas de los propios actores, como por los aportes de estudios antecedentes (Dacal, 2006; AlvarelloS, 2007) - que no se trata de una opción residual por falta de un edificio teatral, sino de una precisa decisión elaborada en el marco de una "democratización cultural." (García Canclinl, 1987).

La principal razón que motiva esta elección político-estética es la premisa que vincula la calle, el espacio público, como lugar ideal para el encuentro con "el pueblo": de ahí la voluntad de acercar el teatro a los "sectores populares", inquietud que tiene sus raíces en las experiencias de teatro militante de los años 1970. (Verzero, 2013).

Poniendo estos términos entre comillas, queremos problematizar la supuesta homogeneidad y el carácter unitario de las clases populares en el discurso de los grupos de teatro callejero: es preciso resaltar, al contrario, la heterogeneidad de la sociedad civil (Dagnino, Olivera y Panfichi, 2006) que se traduce en distintas tendencias político-ideológicas y por ende en diferentes concepciones de la 
actividad artística, trascendiendo el mito del carácter unitario, virtuoso y revolucionario de la clase trabajadora. A su vez, tratamos de complejizar la noción de popular a través de los aportes de los estudios culturales y de la antropología, haciendo hincapié en la ductilidad de este concepto y su carácter dialéctico: aquí, se ha trabajado como contrapunto de hegemónico/culto y se encuentra asociado críticamente a la idea de tradición.

Por otro lado, a través del recorrido histórico del teatro callejero en Buenos Aires, hemos reconstruido algunos hitos de este lenguaje teatral a lo largo de los años, deteniéndonos finalmente en la experiencia del Grupo La Runfla: destacamos su pertenencia al legado del Teatro de la Libertad en los años 80 y su rol central en la organización de la participación ciudadana, a lo largo de la década del 90, en la recuperación del Parque Avellaneda.

Resaltamos a este propósito la necesidad de distinguir entre espacio y territorio, siendo la calle generalmente percibida como un espacio de convivencia fugaz, sobre todo en las grande ciudades. (Matta, 1981).

En base a esto, relatamos algunas estrategias puestas en marcha para la construcción de un territorio teatral en el Parque Avellaneda, situado en la periferia de la ciudad, dando cuenta de los usos de la cultura como recurso (Yudice, 2002) por parte de los actores culturales locales para lograr este objetivo. Hemos trazado a su vez un paralelismo entre la disputa por la recuperación de este espacio periférico de la ciudad de Buenos Aires y por el uso y la gestión del espacio público por parte de las organizaciones ciudadanas junto con los colectivos artísticos con la disputa por el reconocimiento y la legitimación del teatro callejero, percibido como un saber periférico y a menudo asociado al diletantismo, dentro del campo teatral (Bourdieu, 1990). Lejos de ser exhaustivo, el trabajo que aquí presentamos nos servirá como base para seguir profundizando el estudio del teatro callejero en Buenos Aires, siguiendo las múltiples líneas de investigación inauguradas en el presente artículo. 


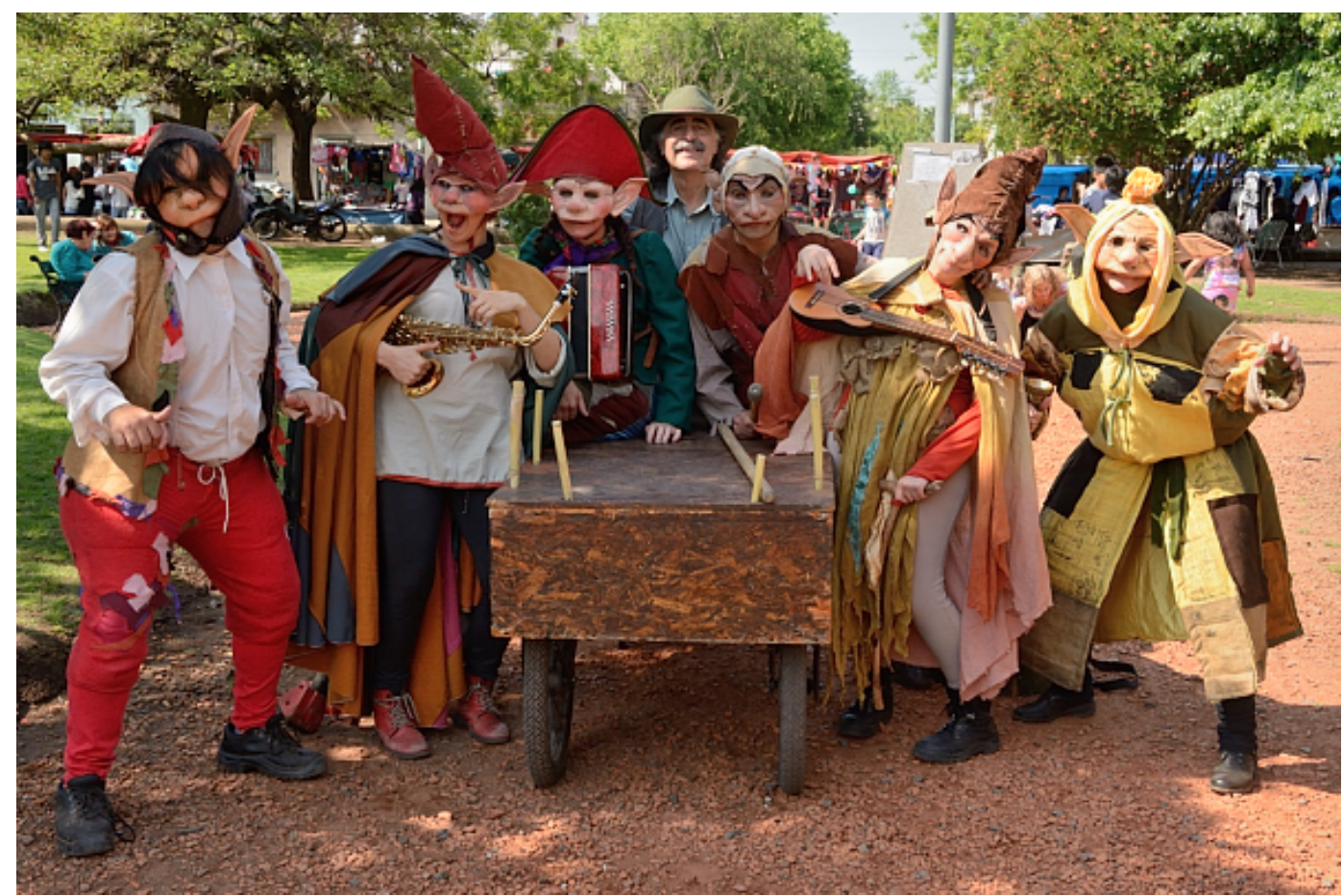

Fonte: http://www.grupolarunfla.com.ar

\section{Referencias}

ACHUGAR, HUGO. Derechos culturales: ¿una nueva frontera de las políticas públicas para la cultura? en Pensar Iberoamérica. Revista de Cultura, no 4, junioseptiembre. Consultado en www.oei.es/pensariberoamerica/ric04a04.htm.

ALVARELLOS, Héctor. Teatro callejero en la Argentina: de 1982 a 2006. De lo visto, vivido y realizado. Buenos Aires: Ediciones Madres de Plaza de Mayo, 2007.

ALVARELLOS, Héctor. El parque como escenario, una historia con presencia. In: MARONESE Leticia (edit.) Cuadernos Pedagógicos. Parque Avellaneda, Rieles de Patrimonio, Buenos Aires, Comisión para la Preservación del Patrimonio Cultural de la Ciudad Autónoma de Buenos Aires, 2009.

ARRECHE, Araceli. Cuerpos a la intemperie. Fondos documentales sobre el Teatro Callejero de Grupos, AINCRIT, Buenos Aires, 2010.

BAJTIN, Mijail. La cultura popular en la Edad Media y el Renacimiento. El contexto de François Rabelais. Buenos Aires: Alianza Editorial, 1994.

BOAL, Augusto. Técnicas latinoamericanas de teatro popular. Buenos Aires: 
Ediciones El Corregidor, 2013.

BOURDIEU, Pierre. Sociología y cultura. México: Grijalbo, 1990.

CERTEAU, Michel de, La invención de lo cotidiano I. Artes de hacer. México: Universidad Iberoamericana / Instituto Tecnológico de Estudios Superiores de Occidente, 2007.

DACAL, Enrique. Teatro de la Libertad. Teatro callejero en la Argentina desde el movimiento grupal de los '80. Buenos Aires: Ediciones Madres de Plaza de Mayo, 2006.

DAGNINO, OLIVERA y PANFICHI. La disputa por la construcción democrática en América Latina. México: Fondo de Cultura Económica, CIESAS, Universidad Veracruzana, 2006.

DELGADO, Manuel. Artivismo y pospolitica. Sobre la estetización de las luchas sociales en contextos urbanos. QuAderns-e. Institu Catalá d'Antropologia, 18 (2), 68-80, 2013. Recuperado de https://www.raco.cat/index.php/QuadernselCA/article/view/274290

FERNÁNDEZ, Clarisa. Antecedentes e historia del teatro comunitario argentino contemporáneo. Los inicios de un movimiento. Aisthesis Santiago, n. 54, 147-174. 2013.

GARCÍA CANCLINI, Néstor. Políticas culturales en América Latina. México: Grijalbo, 1987.

GARCÍA CANCLINI, Néstor. La sociedad sin relato. Madrid: Ed. Katz, 2010.

GONZÁlEZ, María Laura. La Organización Negra. Performances urbanas entre la vanguardia y el espectáculo. Buenos Aires: Interzona, 2018.

GRAMSCI, Antonio. Piove, governo ladro!. Roma: Editori Internazionali Riuniti, 2012.

GRAMSCI, Antonio. Gli intellettuali e l'organizzazione della cultura. Massa: Edizioni Clandestine, 2019.

HALL, Stewart. Notas sobre la desconstrucción de «lo popular». Publicado en: SAMUEL, Ralph (ed.). Historia popular y teoría socialista. Barcelona: Crítica, 1984.

INFANTINO, Julieta. Circo en Buenos Aires: cultura, jóvenes y políticas en disputa. Buenos Aires: INTeatro, 2014.

INFANTINO, Julieta y MOREL, Hernán. Circo, murga y tango en Buenos Aires: Procesos de resurgimiento y Arte Popular en la post-dictadura (1983). Revista Antropolítica. Niterói, n. 38, p.321-347, 1. sem. Universidad Federal Fluminense, 
Niteroi, RN, Brasil, 2015.

MANDUCA, Ramiro y VERZERO, Lorena. Vocación por lo popular en el activismo artístico contemporáneo: temas, lenguajes y dilemas Revista Encuentros Latinoamericanos, segunda época. Buenos Aires, Vol. III, No 2, julio/diciembre, 2019.

MARTÍN, Alicia, Folclore en el Carnaval de Buenos Aires, Tesis Doctoral de Antropología, Facultad de Filosofía y Letras, UBA. Buenos Aires, mimeo, 2008.

MATTA, Roberto da, O universo do carnaval: imagens e reflexões. Rio de Janeiro: Edições Pinakotheke, 1981.

MAURO, Karina La técnica de actuación en Buenos Aires. Elementos para un modelo de análisis de la actuación teatral a partir del caso porteño. 2011. Tesis (Doctorado). Universidad de Buenos Aires, Buenos Aires, 2011.

MAURO, Karina. El actor popular en el teatro occidental. Pitágoras 500, Campinas, v.3, n. 2, 2013.

MERCADO, Camila. Arte y transformación social en Buenos Aires. Análisis de una actuación cultural de teatro comunitario. Cuadernos de Antropología Social/45, Buenos Aires, 2017.

MERCADO, Camila. Trayectorias de teatro comunitario en Buenos Aires. Políticas culturales, autogestión y sentidos del arte en disputa. 2018. Tesis (Doctorado en Antropología). Facultad de Filosofía y Letras, UBA, Buenos Aires, 2018.

PAVIS, Patrice. Diccionario de teatro. Barcelona: Paidós, 1998.

PELLETTIERI, Osvaldo. En torno al actor nacional: el circo, el cómico italiano y el naturalismo. En De Totó a Sandrini. Del cómico italiano al "actor nacional argentino". Buenos Aires: Galerna, 2001.

PROAÑO GÓMEZ, Lola. Teatro y estética comunitaria. Buenos Aires: Biblos, 2013.

RAGGIO, Liliana. Las relaciones entre el campo cultural y el campo del poder. Las politicas culturales en la Ciudad de Buenos Aires 2000-2010. Tesis (Doctorado en Antropología). Facultad de Filosofía y Letras, Buenos Aires, 2013.

RINDONE, Francesca. La construcción de la memoria a través del teatro: una mirada sobre el arte callejero en Buenos Aires. In: XIII Reunião de Antropologia do Mercosul. Anais eletrônicos XIII Reunião de Antropologia do Mercosul, Porto Alegre, 2019.

SÁNCHEZ SALINAS, R., El desafío de ampliar los parámetros interpretativos de los estudios teatrales, en PROAÑO GÓMEZ, Lola y VERZERO, Lorena, Perspectivas políticas de la escena latinoamericana. California: Argus-A, 2017. 
SCHER, Edith. Teatro de vecinos de la comunidad para la comunidad. Buenos Aires: Argentores, 2010.

VERZERO, Lorena. Teatro militante: radicalización artística y política en los años 70. Buenos Aires: Biblos, 2013.

YUDICE, George. El recurso de la cultura. Usos de la cultura en la era global, Barcelona: Gedisa, 2002.

WILLIAMS, Raymond. Marxismo y Literatura. Buenos Aires: Las Cuarenta, 2009.

\section{Páginas web consultadas:}

Página web del Grupo La Runfla: www/grupolarunfla.com.ar/quienes somos (Consultado en: 22 jun.2020).

Recibido en: 29/06/2020

Aprobado en: 28/07/2020 